\title{
KEPEMIMPINAN PRIMAL; STUDI PADA KEPEMIMPINAN PERUSAHAAAN PELAYARAN PT MK SEMARANG
}

\author{
Hari Sucahyowati ${ }^{1}$, Andi Hendrawan ${ }^{2 *}$, Indriyani ${ }^{3}$ \\ 1,2,3 Akademi Maritim Nusantara; Jl Kendeng 307 Cilacap \\ *Corresponding Author. E-mail : andihendrawan007@gmail.com. Telp : 081226470996
}

\begin{abstract}
Abstrak
Peran Kepemimpinan yang sangat strategis dan penting bagi pencapaian misi, visi dan tujuan suatu organisasi, kepimipinan primal merupakan kepemimpinan berdasarkan kecerdasan emosi, diharapkan kepemimpinan primal merupakan tipe kepmimpinan yang akan meningkatkan kinerja dan kesejahtraan masyarakat. Penelitian ini bertujuan untuk menggambarkan kepemimpinan primal di PT MK Semarang. Penelitian merupakan kualitatif dan kuantitatif dengan mengambil sampel 30 orang Karyawan PT MK. Hasil penelitian menunukan bahwa kepemimpian primal dalam kategori baik bahkan untuk Dimensi komptensi hubungan kategorinya baik sekali.
\end{abstract}

Kata kunci: kepemimpinan primal, Perusahaan Pelayaran

\begin{abstract}
The role of leadership is very strategic and important for achieving the mission, vision and goals of an organization, primal leadership is leadership based on emotional intelligence, it is hoped that primal leadership is a type of leadership that will improve the performance and welfare of society. This study aims to describe the primal leadership at PT MK Semarang. This research is both qualitative and quantitative by taking a sample of 30 employees of PT MK. The results of the research show that primal leadership is in a good category, even for the competency dimension of the category relationship is very good.
\end{abstract}

Keywords: primal leadership, Shipping Company

\section{PENDAHULUAN}

Pemimpin sangat mementukan maju tidaknya sebuah organisasi di berbagai tingkatan hingga Negara, kualitas sumberdaya manusianya juga tak kalah pentingnya sehingga dapat menjawab tantangan dari pesatnya perkembangan dan kemajuan jaman. Semakin bertambahnya penduduk negara dan rendahnya pendapatan mengakibatkan timbulnya berbagai masalah salah satunya adalah masalah kinerja.

Suatu organisasi didirikan karena mempunyai tujuan yang ingin dicapai, dalam mencapai tujuannya setiap organisasi dipengaruhi oleh para pelaku yang terdapat dalam organisasi yang bersangkutan. Keberhasilan mencapai tujuan tersebut sangat tergantung pada perilaku dan sikap orang-orang dalam mensinergikan berbagai sumberdaya, terma suk sumberdaya manusia, sumber 
daya alam, ilmu pengetahuan dan teknologi(Hendrawan, Sucahyowati, \& Cahyandi, 2020a)

Peran Kepemimpinan yang sangat strategis dan penting bagi pencapaian misi, visi dan tujuan suatu organisasi, merupakan salah satu motif yang mendorong manusia untuk selalu menyelidiki seluk-beluk yang terkait dengan Kepemimpinan(Hendrawan, Laras, et al., 2020)

Kepemimpinan primal menurut Goleman, Boyatzis, \& McKee (2014) ialah kecerdasan emosional. Dengan kecerdasan emosional pemimpin mampu mengelola kekuasaan dan meningkatkan kinerjanya secara optimal. Berkenaan dengan kecerdasan emosional, (Goleman et al., 2014) telah meneliti konsekuensi ke- cerdasan emosional bagi pemimpin organisasi.

Syarat yang harus dimiliki oleh seorang pemimpin adalah kecerdasan emosional, sebagaimana di katakan oleh seorang Psikolog bernama Howard Garner dalam Steven beliau mengemukakan bahwa adanya inteligensi lain, yang disebut sebagai kecerdasan emosional, dengan kecerdasan tersebut orang pun terbuka wawasannya. Berdasarkan pengamatan dan kejadian dalam masyarakat mengisyaratkan bahwa kecerdasan emosional dapat sama ampuhnya, bahkan terkadang lebih ampuh daripada IQ. Serangkaian studi menunjukkan bahwa orang yang secara intelektual cerdas sering kali bukan orang yang paling berhasil dalam pekerjaannya maupun dalam kehidupan pribadinya.

Para pemimpin besar menggerakkan kita dengan cara membangkitkan semangat dan menginspirasi yang terbaik dalam diri kita. Apapun yang mereka canangkan tergantung pada bagaimana cara mereka melalukannya, bahkan jika segala sesuatunya sudah dipersiapkan dengan benar tetapi pemimpin gagal dalam mengemban tugas mendasarnya yaitu mengarahkan emosi kearah yang benar, maka yang mereka lakukan tidak akan mendapat hasil sebagaimana mestinya. Tugas untuk mengarahkan emosi ini bersifat primal (yang utama). Tugas ini merupakan tindakan yang orisinal sekaligus paling penting dari kepemimpinan. Pemimpin selalu memainkan peran emosi yang primordial, entah ia adalah kepala suku atau kepala adat, direktur, mereka mendapatkan kedudukannya terutama karena kemampuan mereka untuk menggerakan emosi. PT Mk adslah perusahaan pelayaran dipimpin oleh seorang direktur yang yang ditunjuk oleh pemegang saham., keberadaan dan peran direktur sangat vital untuk memberikan kebijakan dan arah pengembangan perusahaan. . Tujuan dari penelitian ini adalah menggambarkan kepemimpinan primal di PT MK Semarang.

\section{KEPEMIMPINAN PRIMAL}

Goleman, Boyatzis, \& McKee (2008) menjelaskan bahwa kepemimpinan berbasis kecerdasan emosi atau Primal Leadership merupakan model kepemimpinan berdasarkan neurologi (otak). Konsep kepemimpinan ini memaparkan bahwa kecerdasan emosi seorang pemimpin dapat menginspirasi sehingga bawahannya tetap termotivasi menjalankan tugas dan memiliki komitmen terhadap organisasi. Pemimpin yang tidak memiliki kecerdasan emosi dapat mengganggu keadaan emosi bawahan di tempat kerja.

Kecerdasan emosi adalah penggunaan emosi secara cerdas atau memanfaatkan emosi tersebut sebagai pemandu perilaku, sehingga hasil perilaku

Majalah Ilmiah Bahari Jogja $\mid 2$ | http://jurnal.amy.ac.id/index.php/MIBJ/ 
seseorang dapat meningkat. Contohnya, ketika seseorang hendak melakukan sebuah presentasi maka yang dilakukan adalah mengurangi kegelisahan dengan melakukan relaksasi ataupun menghentikan tindakan yang kurang menyenangkan seperti berjalan bolak-balik dalam suatu ruangan. Dengan menurunnya kegelisahan, maka dapat melakukan presentasi dengan baik, inilah yang dimaksud dengan meningkatnya hasil perilaku.(Karyanto, 2018).

Kepemimpinan berbasis kecerdasan emosi adalah konsep dimana emosi yang dinampakkan pemimpin sangat berpengaruh pada para bawahan karena pemimpin menjadi pusat perhatian, sebagai orang yang paling didengar pendapatnya dan ditiru perilakunya pada suatu organisasi atau masyarakat.. Ketika anggota bertanya kepada pemimpin, maka jawaban pemimpin yang akan dijadikan sebagai respon atau landasan perilaku yang paling sah. Karena itu, diam atau geraknya pemimpin sangat mempengaruhi respon yang juga harus diaktuskan oleh para bawahan. Pemimpin, tidak semua mamiliki kecerdasan emosi untuk mempengaruhi emosi dari bawahannya. Ketika pemimpin tidak memiliki kredibilitas dalam hal pengelolahan emosi tersebut, maka bawahan dapat mencari bimbingan emosi kepada orang yang dianggap mampu. Penelitian terbaru pun mengungkapkan bahwa aspek kecerdasan emosi (EQ) menjadi pemrediksi yang lebih baik terhadap kinerja kepemimpinan dibandingkan dengan kepemimpinan tradisional yang berpijak pada kecerdasan

Menurut Teori Kepemimpinan Primal, gaya kepemimpinan merupakan proses pemimpin mempergunakan kecerdasan emosionalnya untuk mempengaruhi dan menciptakan emosi kondusif para pengikutnya. Melalui proses itu gaya kepemimpinan mempengaruhi iklim emosional organisasi yang kemudian mempengaruhi kinerja para pengikut dan kinerja organisasi(Iriani, 2016).

\section{DIMENSI KEPEMIMPINAN PRIMAL}

Kepemimpinan berbasis kecerdasan emosi ditandai dengan adanya beberapa kompetensi pada diri seorang pemimpin tersebut.

\section{KOMPETENSI KESADARAN DIRI.}

Pemimpin yang memiliki kesadaran diri dapat mengenali emosi yang terdapat pada dirinya, mengenali bagaimana perasaaan dapat memengaruhi kinerja mereka. Mereka juga mengetahi kapan mereka harus meminta bantuan dan dimana ia harus memusatkan perhatian untuk menumbuhkan kekuatan kepemimpinan yang baru. Mereka juga memiliki kepercayaan diri yang tinggi, oleh karena itu mereka terlihat menonjol dalam kelompok Ahli psikologi bernama Mayer, J. D. Salovey, P. Caruso, (2004) mengungkapkan bahwa sadar diri merupakan salah satu gaya khas seseorang dalam mengatasi emosi diri. Seseorang dapat juga menganut gaya lain, yakni larut dalam permasalahan atau bahkan pasrah dalam menghadapi masalah.Pemimpin yang memiliki kesadaran diri dapat digambarkan dengan kondisi mampu mengenali pengaruh kondisi perasaan yang mereka alami terhadap diri sendiri dan kinerja mereka di dalam organisasi. Biasanya pemimpin yang memilki kesadaran diri tersebut juga dapat menilai diri mereka dengan akurat, seperti mengenali keterbatasan dan kekuatan yang terdapat pada dirinya. Dengan mengenali keterbatasan dirinya, maka dia tahu kapan harus 
meminta tolong kepada orang lain. Namun ketika pemimpin menyadari bahwa dirinya memiliki kemampuan maka pemimpin tersebut memiliki kepercayaan diri sekalipun mendapatkan tugas yang sulit, hal ini yang membuat kehadirannya dapat terlihat sangat mencolok di dalam suatu kelompok atau organisasi.

\section{KOMPETENSI PENGELOLAAN DIRI}

Kompetensi ini dapat dilihat dari kesanggupan pemimpin mengelola emosi diri, bahkan dalam situasi yang sulit. Pengelolaan emosi tidak selalu dapat diartikan menahan atau menekan emosi yang muncul, melainkan memahami emosi untuk kemudian dapat melakukan suatu tindakan yang baik untuk dilakukan.62 Situasi sulit pemimpin antara lain ketika pemimpin memiliki banyak masalah, tidak membuat pemimpin kehilangan fokus atau konsentrasinya hingga masalah tersebut berhasil terpecahkan.

Pemimpin dengan kemampuan ini mampu merumuskan tujuan organisasi secara realistis dan terukur. Ketika ada pemimpin yang menetapkan tujuan dengan tidak menghitung kerealistisan suatu tujuan, atau lebih terpengaruhi oleh keinginan atau ego dirinya, maka dianggap tidak memiliki kemampuan pengelolaan diri yang baik. Tidak berhenti dari kemampuan untuk fokus atau mampu menentukan kebijakan secara realistis, pemimpin dengan kemampuan pengelolaan diri yang baik bahkan dapat memiliki inisiatif hingga keoptimisan dalam bekerja. Kemampuan pengelolaan dirinya dapat dilihat dari inisiatif yang dia munculkan dikala menghadapi masalah. Ketika pemimpin tidak memiliki kemampuan pengelolaan diri yang baik biasanya akan kehilangan fokus dan akan sulit memiliki inisiatif hingga tidak memiliki optimisme untuk memecahkan masalah. Sehingga secara garis besarnya, jika ada pemimpin yang sering kali bingung, kehilangan fokus, kurang bisa memiliki inisiatif, bahkan pesimis dalam menghadapi masalah, belum bisa dikatakan memiliki kompetensi pengelolaan diri yang dimaksudkan dalam teori ini. Ketiga adalah kompetensi kesadaran sosial, pemimpin yang memiliki kompetensi ini dapat memposisikan diri seperti yang dirasakan orang lain, sehingga bisa membangun hubungan yang baik dengan orang-orang dari berbagai latar belakang. Seorang ahli psikologi humanis dan praktisi kesehatan bernama Jean Wipperman (2006) mengungkapkan bahwa empati membuat seseorang dapat memperhatikan kebutuhan sosial yang menuntut tindakan penyikapan, dengan begitu masalah sosial akan menjadi masalah pribadi, dan hal ini membuat pribadi tersebut menjadi bagian dari masyarakat yang sesungguhnya. Sudut pandang kecerdasan emosi memberi penilaian bahwa seseorang dapat dikatakan semakin menjadi warga negara ketika perasaan ibanya terhadap kondisi sosial semakin bertambah.

\section{KOMPETENSI KESADARAN SOSIAL}

Pemimpin biasanya tidak hanya fokus ataupun sibuk dengan kehidupannya sendiri, tetapi dia juga memiliki kesadaran mengenai apa yang sedang terjadi di dalam organisasinya. Misalnya ketika ada upaya-upaya dari bawahan dengan menghidupkan suatu aturan yang tidak dilegalkan oleh organisasi, maka pemimpin ini bisa mengetahuinya karena sadar terhadap apapun yang terjadi di dalam organisasinya. Karena adanya kesadaran sosial terutama dalam berorganisasi, pemimpin dengan kompetensi ini bahkan mampu mengetahui 
kebutuhan hingga mampu menyediakan dirinya ketika diperlukan oleh bawahannya atau pelanggan dari organisasinya. Berdasarkan penjelasan di atas, jika ada pemimpin yang tidak bisa mengerti tentang yang dirasakan atau dibutuhkan orang lain terutama bawahannya, tidak pernah memiliki waktu ketika dibutuhkan oleh bawahannya, maka tidak sesuai dengan kompetensi ini. Lebih parahnya lagi, ketika seorang pemimpin tidak terlalu mengerti tentang hal-hal atau masalah yang sedang terjadi di organisasi yang dipimpinnya, maka belum bisa dikatakan memiliki kompetensi kesadaran sosial menurut teori ini.

\section{KOMPETENSI PENGELOLAAN RELASI.}

Pemimpin dengan kompetensi ini mampu mengelola bawahan dengan baik salah satunya mampu menggerakkan orang atau bawahan dalam menggapai visi dan misi. Maksudnya, pemimpin dengan kompetensi ini tidak hanya sekedar memerintah bawahan untuk mencapai visi misi organisasi, melainkan dia sendiri juga menunjukkan perilaku dan kesungguhan untuk mencapai visi-misi tersebut dalam kehidupan berorganisasi. Hal ini kemudian mampu menginspirasi bawahan untuk mengikutinya.

Pemimpin yang memiliki pengelolaan relasi yang baik dengan bawahan, tidak hanya sekedar mempekerjakan bawahan, melainkan juga mampu mengembangkan potensi bawahannya. Dia bisa membuat bawahannya mampu melaksanakan pekerjaan di dalam organisasinya. Ketika terjadi konflik di dalam organisasi, kemampuan pengelolaan relasi ini diwujudkan dengan mengembalikan lagi hubungan relasi yang baik di dalam organisasi(Goleman et al., 2002). Misalnya ketika ada pertengkaran antar sesama bawahan, maka pemimpin ini mampu meredam atau menyelesaikannya, hingga membangun hubungan dan semangat kerjasama yang baik di dalam organisasinya.

\section{METODE PENELITIAN}

Menurut Meleong (2006) penelitian kualitatif adalah penelitian yang bermaksud untuk memahami fenomena tentang apa yang dialami oleh subjek penelitian misalnya perilaku, persepsi, motivasi, tindakan, dll secara holistic, dan dengan cara deskripsi dalam bentuk kata-kata dan bahasa, pada suatu konteks khusus yang alamiah dan dengan memanfaatkan berbagai metode alamiah. Menurut Sugiyono (2011), metode penelitian kualitatif adalah metode penelitian yang berlandaskan pada filsafat post positivisme, digunakan untuk meneliti pada kondisi obyek yang alamiah, (sebagai lawannya eksperimen) dimana peneliti adalah sebagai instrumen kunci, pengambilan sampel sumber data dilakukan secara purposive dan snowball, teknik pengumpulan dengan tri-anggulasi (gabungan), analisis data bersifat induktif atau kualitatif, dan hasil penelitian kualitatif lebih menekankan makna dari pada generalisasi.

Penelitian menggunakan sampel 30 orang anak buah direktur PT MK Semarang yang terdiri marketing, dokumen, customer service, keuangan, operational. Penelitian dengan cara pemberian kuesioner dan wawancara mendalam untuk mengkaji bagaimna kepepmimpinan primal yang dilaksankan oleh kepala desa dengan dimensi dan indikator pada tabel 1. 
Tabel 1 Dimensi dan indikator kepemimpinan primal

\begin{tabular}{|c|c|c|}
\hline No & Dimensi & Indikator \\
\hline 1 & $\begin{array}{l}\text { mpetensi } \\
\text { sadaran diri }\end{array}$ & $\begin{array}{l}\text { 1. Pimpinan mampu menentukan tindakan yang terbaik dalam situasi } \\
\text { yang kompleks } \\
\text { 2. Pimpinan mampu menjalankan visi/misi organisasi } \\
\text { 3. Pimpinan mampu menerima kritik yang membangun } \\
\text { 4. Pimpinan percaya diri untuk menerima tugas yang sulit }\end{array}$ \\
\hline & $\begin{array}{l}\text { kompetensi } \\
\text { pengelolaan } \\
\text { diri }\end{array}$ & $\begin{array}{l}\text { 1. Pimpinan mampu mengendalikan emosi } \\
\text { 2. Pimpinan mempunyai integritas yang tinggi } \\
\text { 3. Pimpinan mudah beradaptasi dengan perubahan situasi } \\
\text { 4. Pimpinan mampu mendorong karyawan untuk memperbaiki } \\
\text { kinerja }\end{array}$ \\
\hline 3 & $\begin{array}{l}\text { kompetensi } \\
\text { kesadaran } \\
\text { sosial }\end{array}$ & $\begin{array}{l}\text { 1. Pimpinan mampu memahami keinginan bawahan } \\
\text { 2. Pimpinan mampu membuat keputusan tentang kerja sama baik } \\
\text { internal/ eksternal } \\
\text { 3. Pimpinan mampu memenuhi kebutuhan bawahan }\end{array}$ \\
\hline 4 & $\begin{array}{l}\text { kompetensi } \\
\text { pengelolaan } \\
\text { relasi }\end{array}$ & $\begin{array}{l}\text { 1. Pemimpin mampu menjali kerjasama dengan pihal lain } \\
\text { 2. Pemimpin mampu bekerjsama dengan bawahan } \\
\text { 3. Pemimpin mampu berkomunikasi dengan baik }\end{array}$ \\
\hline
\end{tabular}

\section{HASIL DAN PEMBAHASAN}

Hasil penelitian ditunjukan pada tabel 2, memperlihatkan gambaran kepemimpinan primal kepala desa kamulyan.

Tabel 2 Hasil penelitian gambaran kepemimpinan primal

\begin{tabular}{|c|c|c|c|c|c|c|c|c|}
\hline \multirow[t]{2}{*}{ No } & \multirow[t]{2}{*}{ Dimensi } & \multicolumn{6}{|c|}{ Jawaban } & \multirow[b]{2}{*}{$\begin{array}{c}\text { Ketera } \\
\text { ngan }\end{array}$} \\
\hline & & 1 & 2 & 3 & 4 & 5 & $\begin{array}{c}\text { Rata } \\
\text { rata }\end{array}$ & \\
\hline \multirow[t]{5}{*}{1} & kompetensi kesadaran diri & & & & & & 4.19 & Baik \\
\hline & $\begin{array}{l}\text { Pimpinan mampu menentukan } \\
\text { tindakan yang terbaik dalam } \\
\text { situasi yang kompleks }\end{array}$ & 3,3 & 3,3 & 6.7 & 33.3 & 53.4 & 4,10 & Baik \\
\hline & $\begin{array}{l}\text { Pimpinan mampu menjalankan } \\
\text { visi/misi organisasi }\end{array}$ & 3.3 & 6.7 & 3.3 & 33.3 & 53.4 & 4.10 & Baik \\
\hline & $\begin{array}{l}\text { Pimpinan mampu menerima } \\
\text { kritik yang membangun }\end{array}$ & 6.7 & 6.7 & 6.7 & 33.3 & 46.6 & 4.06 & Baik \\
\hline & $\begin{array}{l}\text { Pimpinan percaya diri untuk } \\
\text { menerima tugas yang sulit }\end{array}$ & 3.3 & 3.3 & 3.3 & 36.6 & 53.4 & 4.51 & $\begin{array}{c}\text { Sangat } \\
\text { baik }\end{array}$ \\
\hline \multirow[t]{4}{*}{2} & kompetensi pengelolaan diri & & & & & & 4.09 & Baik \\
\hline & $\begin{array}{l}\text { Pimpinan mampu } \\
\text { mengendalikan emosi }\end{array}$ & 6.7 & 3.3 & 6.7 & 36.6 & 46.6 & 4.12 & Baik \\
\hline & $\begin{array}{l}\text { Pimpinan mempunyai integritas } \\
\text { yang tinggi }\end{array}$ & 6.7 & 6.7 & 6.7 & 36.6 & 43.4 & 4.05 & Baik \\
\hline & $\begin{array}{l}\text { Pimpinan mudah beradaptasi } \\
\text { dengan perubahan situasi }\end{array}$ & 3.3 & 6.7 & 3.3 & 33.3 & 53.4 & 4.10 & Baik \\
\hline
\end{tabular}




\begin{tabular}{llllllll}
\hline & 3.3 & 6.7 & 3.3 & 33.3 & 53.4 & 4.10 & Baik \\
\hline $\begin{array}{l}\text { Pimpinan mampu mendorong } \\
\text { karyawan untuk memperbaiki } \\
\text { kinerja }\end{array}$ & & & & & & & \\
$\begin{array}{l}\text { kompetensi kesadaran sosial } \\
\text { Pimpinan mampu memahami } \\
\text { keinginan bawahan }\end{array}$ & 6.7 & 6.7 & 6.7 & 36.6 & 43.4 & 4.05 & baik \\
$\begin{array}{l}\text { Pimpinan mampu membuat } \\
\text { keputusan tentang kerja sama } \\
\text { baik internal/ eksternal }\end{array}$ & 3.3 & 6.7 & 3.3 & 33.3 & 53.4 & 4.10 & Baik \\
$\begin{array}{l}\text { Pimpinan mampu memenuhi } \\
\text { kebutuhan bawahan }\end{array}$ & 3.3 & 6.7 & 3.3 & 33.3 & 53.4 & 4.10 & Baik \\
$\begin{array}{l}\text { kompetensi pengelolaan relasi } \\
\text { Pemimpin mampu menjali }\end{array}$ & 3.3 & 3.3 & 3.3 & 36.6 & 53.4 & 4.51 & $\begin{array}{c}\text { Sangat } \\
\text { baik }\end{array}$ \\
$\begin{array}{l}\text { kerjasama dengan pihal lain } \\
\text { Pemimpin mampu bekerjsama } \\
\text { dengan bawahan }\end{array}$ & 6.7 & 6.7 & 6.7 & 36.6 & 43.4 & 4.05 & Baik \\
$\begin{array}{l}\text { Pemimpin mampu } \\
\text { berkomunikasi dengan baik }\end{array}$ & 3.3 & 3.3 & 3.3 & 36.6 & 53.4 & 4.51 & $\begin{array}{c}\text { Sangat } \\
\text { baik }\end{array}$ \\
\hline
\end{tabular}

Hasil penelitian menujukan bahwa kepemimponan primal di PT MK Semarag berjalan dengan baik, pada kompensi pengelolaan relasi dipandang sangat baik hal ini bisa dimaklumi karena latar belakang pendidikan dan pengalaman sang Pimpiman sangat berpengalaman karena sudah cukup lama di dunia pelayaran, sehingga cara berkomunikasi sudah mumpuni Pengalaman sebagai sebagai direktur sebelumnya menjadi modal kepemimpinan primal sehingga bisa mngatasi permasalahan yang ada di PT MK Semarang.

Menurut Hendrawan, Indriyani, et al (2020) Pada dasarnya konflik merupakan sesuatu yang tidak dapat dihindarkan, adanya konflik dapat membuat organisasi menjadi lebih kuat atau bahkan hancur, tergantung bagaimana cara pemimpin dalam menangani konflik yang ada. Jika ada konflik, pemimpin dihadapi dengan situasi sulit yang menuntutnya harus bersikap dengan tepat(Hendrawan, 2018). Pemimpin primal sedapat mungkin bisa mengendalikan emosi dan menggunakan kecerdasanya untuk mengendalikan bawahan dan memotivasi bawahan sehingan tranformasi pengetahuan dan pekerjaan dalam terjalin dengan baik dan tujuan oragnisasi dapat tercapai(Hendrawan, Laras, et al., 2020). Kepemimpinan di PT MIK semarang akan lebuh bermakna jika didukung oleh prilaku organizational citizenship behavior (OCB). Penelitian Hendrawan, Sucahyawati, \& Indriyani, (2017) menunjukan bawa prilaku OCB akan membuat iklim organisasi menjadi lebih kondusif sehingga kepemimpinan akan lebih bisa terlaksana untuk mencapai tujuan dan visi misi PT MK Semarang. Kinerja perusahaan yang baik karena pemimpin yang bisa memotivas sehingga iklim (Hendrawan et al., 2020) berbgai pengetahuan antar karyawan berjalan dengan baik sehingga akan memunculkan saling kerja sama yang pada ujungnya meningkatkan nilai marketing perusahaan(Hendrawan et al., 2018; Hendrawan, Sucahyowati, et al., 2019, 2020; Sucahyowati \& Hendrawan, 2020).

Pemimpin yang primal akan mempu memotivasi masyarakat untuk menjadi kreatif dan inovatif dengan segala cara. Menurut Hendrawan (2017); Hendrawan, Kuswantoro, \& Sucahyowati (2019) bahwa kreativitas dan inovasi merupakan hal yang harus dilakukan untuk pengembangan dan kemajuan masyarakat. Desa 
kamulyan merupakan desa yang kreatif karena di bawah kepemimpinan Direktur yang sekarang telah menunjukan kemajuan yang baerarti antara kain nilai kinerja yang meningkat sehingga kesejahteraan juga meningkat. . Penelitian Fitry, Wirawan, \& Supriyadi (2017) Kepemimpinan Primal berpengaruh signifikan terhadap Kinerja, artinya bawa pola kepemimpinan primal yang laksanakan akan meningkatkan kinerja yang pada akhirnya meningkatkan kesejahteraan karyawan. Memotivasi bawahan dan masyarakat menjadi keharusan agar visi dan misi lembaga terwujud, dalam penelitian Hendrawan, Sucahyowati, \& Cahyandi (2020) motivasi sangat erat hubungan dengan prilaku OCB dan peningkatan kinerja, kepemimpinan primal yang bisa memotivasi bawahan dan masyarakat merupakan hal yang bisa mewujudkan kesejahteraan karyawan pada umumnya.

\section{KESIMPULAN}

Kepemimpinan primal di PT MK Semarang pada umumnya berjalan dengan baik, bahkan untuk dimensi hubungan sangat baik, kepemimpinan primal di PT MK Semarang telah membawa masyarakat desa kamulyan lebih sejahtera dengan mencapai visi dan misinya. Kepala desa berhasil memotivasi warganya agar semangat bersama membangun desa dan bersama sama mengatasi permasalahan yang ada di antara mereka. Semangat gotong royong yang ditumbuhkan kepemimpinan yang berdasarkan kecerdasan emosi telah berasil karena kepala desa dengan sabar dan perhatian memperhatikan masukan masukan dan keluhan warga, yang pada akhirnya menjadi pertimbangan dalam menyusun kebijakan. Kepemimpinan dengan dimensi hubungan sanagat baik ditunjukan dengan keberhasilan kepala desa menyatukan warga dalam satu visi dan misi, permasalahan bisa diselesaikan melalui permuswarahan. .

\section{DAFTAR PUSTAKA}

Fitry, S. B., Wirawan, \& Supriyadi. (2017). PENGARUH KEPEMIMPINAN PRIMAL DAN PROFESIONALISME TERHADAP KINERJA MELALUI KEPUASAN KERJA (Studi Kasus pada Perwira Pertama dan Perwira Menengah di Lingkungan Mabes Polri). Markas Besar Kepolisian Negara Republik Indonesia, 41-57.

Goleman, D., Boyatzis, R., \& McKee, A. (2002). PRIMAL LEADERSHIP. Daniel Goleman All Rights Reserved.

Goleman, D., Boyatzis, R., \& McKee, A. (2008). Primal Leadership: Unleashing the Power of Emotional Intelligence. Primal Leadership.

Goleman, D., Boyatzis, R., \& McKee, A. (2014). Primal Leadership : The Hidden Driver of Great Performance. Harvard Business School Publishing Corporation.

Hakim, A. R., Wibowo, W., Astriawati, N., Prodi, A., Kapal, P., Tinggi, S., ... Maritim, T. (2020). SISTEM PENDINGIN MESIN DIESEL PADA WHELL LOADER KOMATSU WA120-3CS. Teknovasi, Jurnal, 07, 76-85. Hendrawan, A. (2017). KOMPETENSI DAN KRATIVITAS TIM PADA UMKM DI WILAYAH KECAMATAN BANTARSARI KABUPATEN CILACAP. 
Seminar Nasional Dan Call Paper SINEMA 2 Fakultas FIB Universitas

Ngeri Surabaya, 5 Oktober 2017, 264-275.

Hendrawan, A. (2018). Pengembangan Kompetensi UMKM dengan Pembelajaran

Organisasi. Jurnal Inovasi Bisnis Dan Manajemen Indonesia, 1(4), 489-496.

Hendrawan, A., Kuswantoro, F., \& Sucahyowati, H. (2019). Dimensi Kreativitas dan Pengembangan Usaha Mikro Kecil dan Menengah ( UMKM ). Jurnal Hummansi, 2(1), 25-36.

Hendrawan, A., Laras, T., Sucahyowati, H., \& Cahyandi, K. (2020).

PENINGKATAN KEPEMIMPINAN TRANSFORMASIONAL DENGAN

ORGANIZATIONAL CITIZENSHIP BEHAVIOR (OCB. 1-16.

Hendrawan, A., Sasongko, A., \& Sukmono, S. (2017). ANALISIS

THERMODINAMILA KETEL PADA PEMBANGKIT LISTRIK TENAGA OTEC (OCEAN THERMAL ENERGI CONVERSION). Jurnal Saintara, l(2).

Hendrawan, A., Sucahyawati, H., \& Indriyani. (2017). ORGANIZATIONAL

CITIZENSHIP BEHAVIOR (OCB) PADA KARYAWAN AKADEMI

MARITIM NUSANTARA. Prosiding Seminar Nasional UNIMUS

Semarang, 39-48.

Hendrawan, A., Sucahyowati, H., \& Cahyandi, K. (2018). E-COMMERCE IN

SMALL AND MEDIUM ENTERPRISES (SMEs) IN ORDER TO

IMPROVE PERFORMANCE. Jurnal Terapan Manajemen Dan Bisnis, 4(2), 202-207.

Hendrawan, A., Sucahyowati, H., \& Cahyandi, K. (2020a). AVOID

LEADERSHIP PENGARUHNYA TERHADAP KINERJA DAN

ORGANIZATIONAL CITIZENSHIP BEHAVIOR (OCB). 7thNCAB 2020

NATIONAL CONFERENCE APPLIED BUSINESS, .

Hendrawan, A., Sucahyowati, H., \& Cahyandi, K. (2020b). MOTIVASI KERJA

DAN ORGANIZATIONAL CITIZENSHIP BEHAVIOR PADA

KARYAWAN PT MK SEMARANG. Jurnal Administrasi Dan

Kesekretarisan, 5(1), 74-87.

Hendrawan, A., Sucahyowati, H., Cahyandi, K., Indriyani, \& Rayendra, A. (2019). Pengaruh Marketing Digital Terhadap Kinerja Penjualan Produk UMKM Asti Gauri di Kecamatan Bantasari Cilacap. Jurnal Administrasi Dan Kesekretarisan, 4(1), 53-60.

Hendrawan, A., Sucahyowati, H., Laras, T., Stress, P., Terhadap, K., Umkm, P., ... Kabupaten, B. (2020). PENGARUH STRESS KERJA TERHADAP KREATIVITAS PADA TENAGA KERJA PADA UMKM DI WILAYAH BANTARSARI KABUPATEN CILACAP. AmaNU: Jurnal Manajemen Dan Ekonomi, 3(1), 55-72.

Hendrawan, A., Sucahyowati, H., Rayendra, A., Maritim, A., \& Cilacap, N. (2020). BERBAGI PENGETAHUAN DAN PEMBELAJARAN ORGANISASI. Jurnal Ilmu Komunikasi Dan Bisnis, 5(2), 172-186.

Iriani, E. D. (2016). PENGARUH ANTARA KEPEMIMPINAN PRIMAL, BUDAYA ORGANISASI DAN QUALITY OF WORK LIFE DENGAN PERILAKU KEWARGAAN ORGANISASI. Jurnal Citra Widya Edukasi, $\operatorname{VIII}(2), 92-108$. 
Jean Wipperman. (2006). Meningkatkan Kecerdasan Emosional. Jakarta: PT Prestasi Pustaka Raja.

Karyanto, R. (2018). KEPEMIMPINAN BERBASIS KECERDASAN EMOSI

(Studi Pada Komunitas Pelajar Tanpa Pacaran dan Remaja Masjid Ar-

Rahman Surabaya). PASCASARJANA UNIVERSITAS ISLAM NEGERI SUNAN AMPEL SURABAYA.

Mayer, J. D. Salovey, P. Caruso, D. R. (2004). Emotional Intelligence: Theory, Findings, and Implications. Psychological Inquiry, 15(3), 197-215.

Purjiyono, Ningrum Astriawati, P. S. s. (2019). Perawatan Sistem Pelumasan Mesin Utama Pada Kapal Km. Mutiara Sentosa Ii. Teknovasi, 06, 74-80.

Sucahyowati, H., \& Hendrawan, A. (2020). PENGARUH EMPLOYEE

ENGAGEMENT TERHADAP KINERJA KARYAWAN PADA PT MK

SEMARANG. Jurnal Sains Teknologi Transportasi Maritim, 2(2), 9-15.

Sugiyono. (2018). Metode Penelitian Kuantitatif,Kualitatif dan R\&D. Ke-26. 